\title{
Modern warming, medieval and ancient optimums as the result of orbital changes in the Earth-Moon-Sun system
}

\author{
Larisa Litvinenko ${ }^{1,{ }^{*}}$, Victoria Litvinenko ${ }^{1}$ \\ ${ }^{1}$ Moscow Region State University, 10A, Radio str, 105005, Moscow, Russia
}

\begin{abstract}
The root cause of modern climate warming is the influence of gravitational forces on the geospheres of our planet, determined by the orbital configuration of the Earth-Moon-Sun system. The annual changes in the position of the total vector of gravitational forces in space visually reflects the movement of the shadow cone of solar eclipses around the globe. The aim and novelty of the study is to identify the relationship between the number of years with four to five polar eclipses (in periods of pessimums, their number reaches 15-17 years, and in periods of optimums - 2-7 years in a century) and glaciation processes, such as the Fernau fluctuation, Late Antique Little Ice Age, or processes of warming and degradation of glaciers in the Roman and Medieval optimums. The research methods were study, generalization of materials, data synthesis, logical and graphical analysis. The anthropogenic causes of modern warming, which will last until the middle of the 22nd century, are secondary. In the second half of the 22 nd century, and throughout the entire 24th century, the advance of the alpine glaciers will be associated with the conditions of the climatic pessimum. Solar activity, planetary factors and processes - volcanic activity, current intensity, heat transfer with the World Ocean - can noticeably strengthen or weaken both the manifestation of optimums and pessimums. The results of the study, taking into account other factors, can be used in the retroanalysis of the periods of glaciation in centuries before the Common Era and the prediction of them in the future.
\end{abstract}

\section{Introduction}

One of the main problems of mankind is a reliable assessment of the climate change trend. Modern warming indicates a thermodynamic violation in the thermal balance of the planet Earth. This may be due to both planetary and cosmic climate-forming factors and processes. An international group of climate experts associates an increase in air temperature with an increase in $\mathrm{CO}_{2}$ concentration as a result of anthropogenic impact [1]. At the same time, many scientists are convinced that this is one of the historical stages of the natural fluctuation of global temperature $[2,3,4]$. They explain the increase in carbon dioxide by the "buffer" activity of the oceans, which can absorb it during the cooling

\footnotetext{
*Corresponding author: larisa-litvinenko@yandex.ru
} 
period, and during the warming period - release it into the atmosphere several times more than the entire world industry. Researchers do not deny the full consequences of anthropogenic activity. However, they do not always succeed in explaining centennial climate variations only by volcanic activity and changes in solar activity.

Climate change problem is as old as the world. It worried scientists at all times, and they tried to give this phenomenon an assessment. In the 1st century AD, Lucius Junius Moderatus Columella wrote: "I know that many remarkable writers were convinced of the climatic changes taking place over a long period. Hipparchus, the most knowledgeable teacher of astronomy, said that the time would come when the world poles would budge, and such a respectable agricultural writer as Sazerna apparently believed him. In his book on agriculture, he understands this climate change in such a way that areas in which earlier, due to the long and severe winter, it was impossible to grow a single grape or oilseed shoot, now, due to the warming and disappearance of the former cold, will be covered with olives and grapes" [5].

\section{Literature Review}

The basis of any forecasting is the search for empirical relationships that allow catching the rhythms caused by natural physical processes, and describing them by statistical relationships of various meteorological parameters [6, 7, 8]. Attempts of scientists to identify the cyclical or rhythmic processes especially intensified in the late nineteenth and twentieth centuries [9-15]. It becomes possible to understand Le Roy Ladurie [16], who criticized the nineteenth-century cyclomania, but it was a natural process of finding the causes of climate fluctuations.

The 11-year cycle most used in research is associated with solar activity. A number of authors also explain identified rhythms $(4,7,8,14,22$ years) in connection with 11-year solar activity $[10,11]$.

However, many planetary rhythms - 3, 4, 7, 8, 11, 18, 22, 29, as well as multiples of 18 , such as 36, 54, 72, 90, 108 years $[17,18]$, are formed by the celestial mechanics of the Moon, Earth and Sun in the lunar-solar calendar of events. They are caused by gravitational forces, periodically causing acceleration of motion and rotation of the planet Earth and the reverse responses of its geospheres [19]. Centuries-old rhythms are associated with changes in the Moon-Earth-Sun orbital configurations, which are visually observed in the annual movement of the shadow cone of solar eclipses or the total vector of gravitational forces around the globe. Mathematically, these forces, including those causing an uneven acceleration of the motion and rotation of the planet, can be described in various ways [20, 21].

\section{Materials and methods}

The synchronization of the gravitational forces of the Moon and the Sun during the period of solar eclipses lasts 30-34 days. Solar eclipses are combined in the saros series, which consist of 69-87 eclipses. They gradually pass from partial eclipses in the polar regions to circular and total ones, then again to partial eclipses at the opposite pole. The time interval between eclipses in saros is 18 years and 11 days. The saros series lasts about 1226-1550 years, generating centennial rhythms. The difficulty in finding ways of long-term forecasting is caused by the fact that the Earth makes more than a dozen movements in outer space, in addition, its satellite is gradually moving away. There are almost no completely identical situations, including those with solar eclipses [22, 23]: years differ in 
the timing of the onset of events, the configuration of celestial objects, the distance from the Earth to the moon's shadow cone, the territory it passes over the planet's surface, etc.

Polar eclipses occur when a series of saros begins or ends. During 180-200 years of this series (10-11 eclipses), sometimes more, the axis of the moon's shadow cone does not cross the planet's surface, being located at a considerable distance above the pole (up to 9-10 thousand $\mathrm{km}$ from the center of the Earth, with an average radius of $6371 \mathrm{~km}$ ). As the shadow cone approaches the surface of the Earth, polar eclipses can be not only partial, but also full or ring-shaped. Their maximum number per year reaches 5. Polar eclipses can follow for 2 consecutive years, but their total combination for this period also varies within three to five eclipses.

It was revealed that years with two or four polar eclipses, and especially those in which the saros series begin or end, are often cold with severe winters in the Russian Plain and Europe, often with a lot of rainfall and floods [18]. For example, 1870, 1888, 1942, 1978, 1996, united by the saros series $115,148,153$.

In addition to the polar years, the years with two non-polar eclipses are often cold and rainy, one of which takes place in the Pacific Ocean off the coast of America, the second in the southern hemisphere or in southern Eurasia with the direction of the motion vector from the mainland to the southeast or northeast into the Pacific Ocean.

The most used research methods in the work were the study and synthesis of materials on climate and its restoration in the historical era [24-36], alternating years with solar eclipses from $3000 \mathrm{BC}$ up to $3000 \mathrm{AD}[22,37]$, as well as logical, graphical analysis, and synthesis of the obtained data. Open access to the materials of the site is of great importance for the appearance of the results [22].

\section{Results}

Table 1 shows the intervals between years with four and five polar eclipses over centuries, which are the result of the motion of the Moon and the Earth in outer space and the rotation of their orbits. The analysis of the repeatability of years with four and five polar eclipses over the centuries gave interesting results: in the first, sixth, seventh, twelfth, thirteenth, seventeenth, and eighteenth centuries, the number of years with 4-5 polar eclipses was maximum - 15-17 cases (Figure 1, table 1). Various authors attribute these centuries to periods of cooling and the advance of alpine glaciers. In the twenty-fourth century, the number of such years will reach 18 cases (Table 1, Figure 1).

Table 1. Rhythms of years by centuries between years with four and five polar eclipses.

\begin{tabular}{|l|l|l|l|}
\hline Century & $\begin{array}{c}\text { Number of } \\
\text { years with four } \\
\text { eclipses }\end{array}$ & \multicolumn{1}{|c|}{$\begin{array}{c}\text { Intervals between years with four and five } \\
\text { polar eclipses }\end{array}$} & $\begin{array}{c}\text { Transition to } \\
\text { the next } \\
\text { century }\end{array}$ \\
\hline I & $14+2$ (five) & $3,4,4,7,7,4,7,4,7,11,7,3,8,7,4$. & 7 \\
\hline II & $10+1$ (five) & $7,4,7,11,7,11,11,7,11,18$. & 18 \\
\hline III & 5 & $11,18,18,29$. & 65 \\
\hline IV & 2 & 18. & 98 \\
\hline V & 4 & $4,14,11$. & 7 \\
\hline VI & 17 & $11,7,4,7,4,3,4,7,4,7,7,4,7,4,7,3$. & 8 \\
\hline VII & $13+2$ (five) & $7,11,7,11,7,4,7,3,4,4,7,4,7,11$. & 7 \\
\hline VIII & $7+1$ (five) & $11,18,11,7,11,18,18$. & 11 \\
\hline IX & 4 & $18,47,18$. & 18 \\
\hline X & 5 & $11,18,18,33$. & 18 \\
\hline XI & 11 & $18,18,7,8,3,11,7,11,4,3$. & 4 \\
\hline XII & 17 & $7,4,3,4,4,7,7,11,7,11,7,4,3,4,4,7$. & 7 \\
\hline XIII & $14+1$ (five) & $4,7,4,3,4,7,4,7,11,7,4,7,11,7$. & 11 \\
\hline
\end{tabular}




\begin{tabular}{|l|l|l|l|}
\hline XIV & 7 & $7,11,11,18,18,29$. & 18 \\
\hline XV & 6 & $18,11,18,18,18$. & 11 \\
\hline XVI & 4 & $18,47,18$. & 22 \\
\hline XVII & 16 & $7,4,7,7,4,7,4,7,7,4,7,7,4,4,3$. & 11 \\
\hline XVIII & 16 & $7,11,4,7,7,4,3,4,4,7,7,4,7,7,4$. & 7 \\
\hline XIX & $10+1$ (five) & $4,7,7,4,7,11,7,11,11,10$. & 37 \\
\hline XX & $5+1$ (five) & $18,11,18,18,18$. & 11 \\
\hline XXI & 6 & $18,18,18,11,18$ & 18 \\
\hline XXII & 11 & $22,7,11,7,11,7,4,7,7,4$. & 7 \\
\hline XXIII & $11+1$ (five) & $11,11,7,11,11,4,3,11,7,4,7$. & 11 \\
\hline XXIV & 18 & $7,7,4,4,3,4,7,4,3,4,7,4,7,11,3,8,8$ & \\
\hline
\end{tabular}

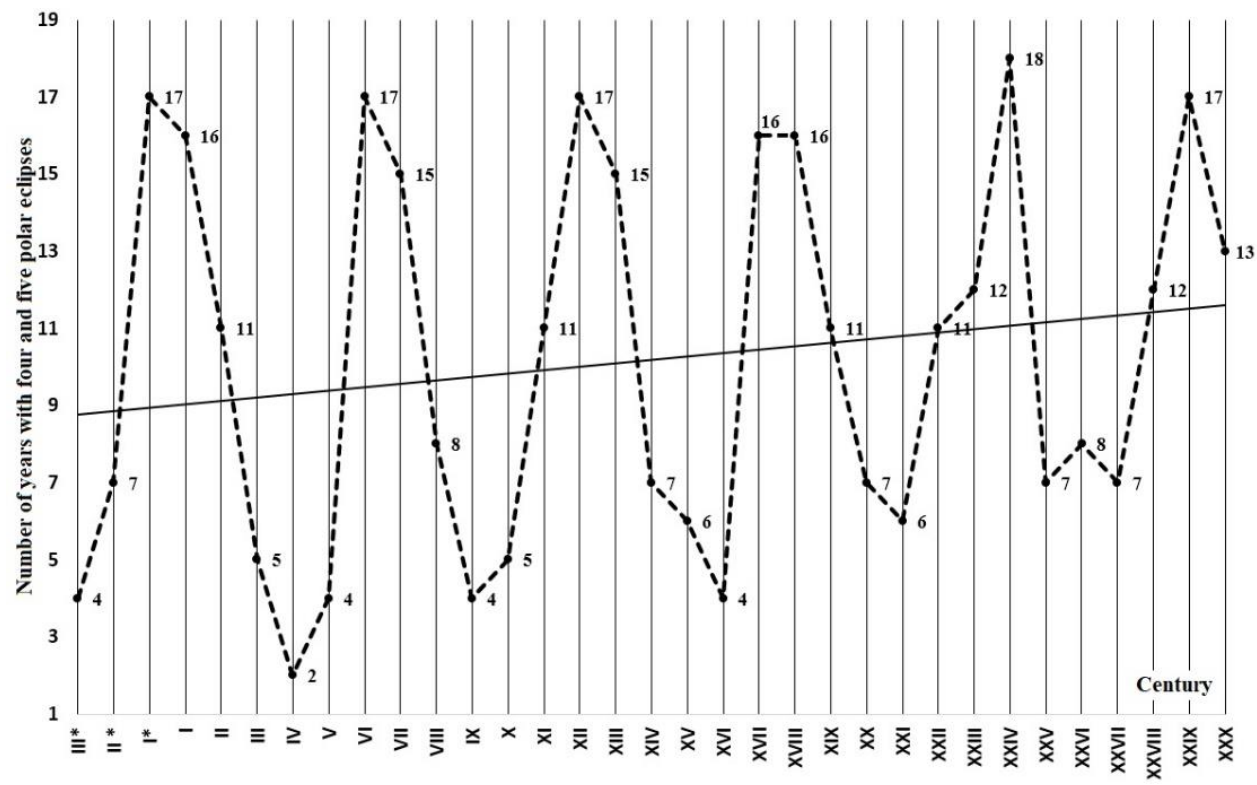

Fig. 1. Change in the number of years with four and five polar eclipses from the III * century BC to XXX century A.D.

In the modern period, as in the 14th and 15th centuries, the number of years with four and five polar eclipses amounted to 6-7 cases (Figure 1, Table 1), in the eighth century -8 years.

In Ancient and Medieval optimums (III-V and IX-X centuries, respectively), the number of years with four and five polar eclipses was reduced to 2-5 cases (Figure 1, Table 1). Analysis of the graph (Figure 1) shows that in over a three-thousand-year time interval, there is a slight tendency to increase in the number of years (from 9 to 11) with four and five polar eclipses.

By the way, all the time intervals between years with polar eclipses calculated in Table $1(8,18,22,29,33,47,65$ and more) are composed of simple intervals of the lunar-solar calendar $-3,4,7,11$ years. It is interesting that at the end of the period of the Roman optimum, the interval between years with 4-5 polar eclipses reached 65 (289-354) and 95 (372-470) years (Table 1).

\section{Discussion}

The Little Ice Age, which covered the territory of Europe and its water area, is well described. Its end was determined by the 19th century. However, different authors, even in 
the same work, refer the beginning of the Little Ice Age to the 13th, 14th or 16th [38] centuries. We adhere to the opinion of Le Roy Ladurie [16], whose diligent study indicates the dates of the inter-century phase of the advance of alpine glaciers, also called the Fernau fluctuation, between 1600(1590)-1850. The Little Ice Age is explained by a decrease in the level of activity of the Sun and the Gulf Stream, volcanic activity, but, probably, these reasons are secondary. Most likely, orbital factors are in the first place, as evidenced by the sharp increase in the number of years with 4-5 polar eclipses in the 17th-18th centuries, as well as in the 12th-13th, 6th-7th centuries, in the I century AD and I century BC - to 15-17 cases in a century (Figure 2).

Years of polar eclipses are usually cold, and their frequent recurrence with the rhythms of years equal to $3,4,7$, and in combination with years of non-polar eclipses, the configuration of which also contributes to the formation of negative temperature anomalies in Europe, leads to a decrease in the overall temperature level over a century. In the seventeenth and eighteenth centuries, the Maunder minimum was superimposed on the orbital factors - a period of prolonged (from 1645 to 1715) decrease in the number of sunspots, which intensified the cooling processes and the development of glaciers in the region.

The Bunte Moor peat bog formed at the foot of the alpine glaciers over millennia turned out to be quite a find for researchers. According to Le Roy Ladurie, the stratigraphic chart compiled by Franz Mayr [39], although it gives a simplified idea of the time of deposition of peat layers in the Bunte Moor bog, but clearly indicates the five main glaciation periods over the past 3500 years. One of these periods is a maximum development of alpine glaciers in 1590-1850, the second - literally according to the book "A History of Climate Since the Year 1000": "a short-term advance in the Middle Ages between 1200 (possibly 1150 ) and 1300 (possibly 1350)" [16]. In addition to a stratigraphic analysis of the location of the medieval moraines of the Fernau Glacier [39], the information found in archival materials finally convinced Le Roy Ladurie in the idea of cooling in the 12-13 centuries, although smaller than in 1590-1850 (Figure 2).

It is this "short-term", but almost two-century period of the advance of glaciers - the Little Ice Age of the post-optimum (12th-13th centuries) that many scholars often omit in their analytical descriptions or refer to the Medieval optimum.

The unification of the Little Ice Age (1590-1850) with the Climatic pessimum of the 1213th centuries (Little Ice Age of the post-optimum) also contradicts historical facts, since in the deposits of the variegated Bunte Moor bog, moraine sands of these two ice ages are separated by a peat layer $[4,39]$. This indicates the presence of relatively favourable time intervals in the XIV-XVI centuries for the accumulation of plant debris.

During optimum periods (Antique, Medieval, Modern warming period), the intervals between years with four polar eclipses increased and amounted to 11, 18, 29 and more years (Table 1), and the number of years with eclipses decreased to 2-6 per century (Figure 1). Probably, the XIV-XVI century is an optimum that did not take place in the classical sense, although there were orbital prerequisites for it. In this Interglacial period of the 1415 th centuries (Figure 2), the number of years with four eclipses did not exceed seven per century (4-7), but the Spörer minimum (1450-1540), which characterizes an almost century-long decrease in solar activity, and maybe other unaccounted factors played a certain role in lowering the temperature. This period was characterized by significant interseasonal and interannual fluctuations in weather conditions [25, 26, 27, 35]. The upper limit of the reconstructed average annual temperature anomaly [27] in the XIV-XVI centuries (Figure 2) was $-0.14 \ldots+0.36^{\circ} \mathrm{C}$, while in the Climatic pessimum of the XIIXIII centuries it was lower, from minus 0.22 up to plus $0.26^{\circ} \mathrm{C}$.

It should be noted that, in addition to the Fernau fluctuation (1590-1850) confirmed by historical documents, there are no clearly defined time boundaries in the dates of the 
advance of glaciation and optimums. For example, in the division of climatic cycles proposed by some authors [40], periods of optimums and periods of advance of glaciers are mixed together: 0-400 - Roman climatic optimum, 400-1000 - Climatic pessimum of the early Middle Ages, 1000-1300 - Medieval climatic optimum, 1300-1850 - the Little Ice Age. The problem is that in radioisotope measurements, the error ranges from \pm 100 years $[16,41]$ to \pm 35 years [4], which sometimes covers the intervals of glaciations and optimums, which last 100-250 years. Absolute trust in radiocarbon dating and underestimation of paleoclimate data, as M.G. Grosswald writes in the book "Half a Century in Search of the Echoes of the Great Glaciations" [42, p. 214], is the Achilles heel of all constructions. In this regard, accurately dated historical evidences are of great importance, but their number has decreased exponentially in the centuries.

From open sources it is known that in the Mediterranean, where social life was most active at the beginning of the first millennium, recorded floods have a peculiar rhythm. The largest number of floods (six or more) was noted at the beginning of the first millennium [38], as well as in the sixth and seventh centuries, in which the number of years with 4-5 polar eclipses reached 15-17, and their rhythm was 3, 4, 7 years (Figure 1, table. 1). In the era of Roman warming, the number of floods decreased to two, and the number of years with four and five polar eclipses - up to 2-5 cases. The work [38] provides information that "after $174 \mathrm{AD}$ and up to $489 \mathrm{AD}$, the climate in Italy became drier. During this time, only two years with floods were noted. After 489, Italy returned to a more humid climate. So, between 489 and 717, 18 floods have already been recorded".

Climate reconstruction of the Russian Plain, North-Eastern Europe, the Arctic and extratropical latitudes of the Northern Hemisphere over the past 2000 years, performed by Klimanov V.A., Klimenko V.V., Matskovsky V.V., Pakhomova L.Yu., Sleptsov A.M., Linderholm H.W., Ljungqvist F.C. et al. [24, 25, 26, 27, 34, 35] and presented in the form of changes in average annual temperatures and their anomalies over a centuries-old period, are in good agreement with the number and rhythm of years with 4-5 polar eclipses over centuries. Climatic chronology $[25,27]$ indicates a steady decrease in temperature since the end of the 5th century, a tendency to decrease over two centuries (VI-VII), and a significant negative temperature anomaly in the middle of the sixth century. The location of the medieval moraines of the Fernau glacier in the Bunte Moor peat bog also indicates a significant advancement of his tongue during this period [16].

In recent years, an international team of scientists led by Professor Ulf Büntgen, and with the active participation of Russian scientists and researchers, doctors of historical and biological sciences V.S. Myglan and A.V. Kirdyanov, using complex (dendrochronological, glaciological, palynological, limnological, historical) surveys in Altai and the Alps, established the start and end dates of the Late Antique Little Ice Age from 536 to about 660 $\mathrm{AD}$ [30]. The peak of cooling occurred in the middle of the "dark" sixth century, when volcanic activity intensified in 536, 540 and 547. It is confirmed by the presence of volcanic ash in the corresponding layers of ice cores [29, 30, 33]. The historical chronicles of John Bishop of Ephesus and the Byzantine writer Procopius of Caesarea also indicate that in 535-536, the Sun darkened and emitted light like the Moon for 18 months [33]. In addition, on the first of September 536, a ring-shaped solar eclipse took place, the coneextension of the lunar shadow of which crossed the territory of Greenland, Iceland, Great Britain, Sardinia, northeast Africa and south-west of the Arabian Peninsula. In the last interpretation of the inscriptions of the Rök runestone, the Scandinavian researchers [43] note the motives of the allegorical description of the struggle between heat and cold, life and death, and the happy return of the Sun after many years of darkness, which they associate with the climate crisis of 536 year. 


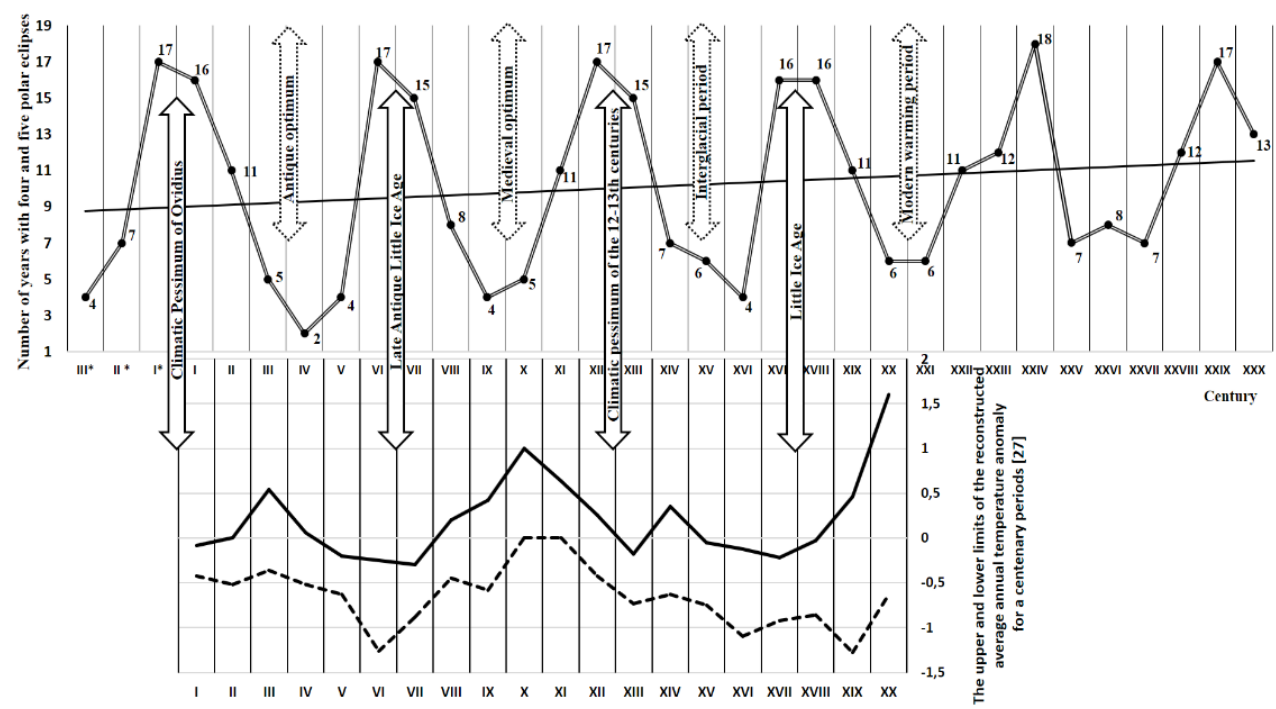

Fig. 2. Change in the number of years with four and five polar eclipses from the III* century BC to XXX century AD and fluctuations in the upper and lower limits of annual average temperature anomalies over a century.

A steady decrease in temperature in the sixth century coincides, as already mentioned, with an increase of the number of years with 4-5 polar eclipses to 17 cases in a century (506, $517,524,528,535,539,542,546,553,557,564,571,575,582,586,593,596)$ and a decrease in the intervals between them to 3-7 years, and in $535,539,542,546$ - to 3-4 years. The catastrophic temperature anomaly of this century, which has covered several regions of Eurasia, is most likely the result of superimposed activation of volcanic activity $(536,540$, and 547$)$ on cooling caused by orbital causes.

It was indicated above that the rhythms of years with four polar eclipses in the first century AD show repeatability of intervals of 3, 4, 7, less often 11 years, which corresponds to centuries of lower reconstructed average annual temperature [27, 35] and the development of glaciers. But, probably, the cooling began even earlier - in the first century $\mathrm{BC}$, when from $77 \mathrm{BC}$ to the $119 \mathrm{AD}$, the ice age of 3, 4, 7 years "turned on".

A number of authors attribute the first century of our era to the Ancient optimum, but it is mentioned in the work of Borisenkov E.P. and Pasetsky V.M. [38] that "in Italy, humid climate was noted between $200 \mathrm{BC}$ and 170 AD. During this time, 22 years with floods were recorded on the Tiber River". Klimenko V.V. [44, 45], analyzing the number of shipwrecks from April to October by centuries, distinguishes the 1st and 5th centuries BC, when their number reached 36-37 and 30 cases, respectively. These data collected by $\mathrm{H}$. Gundel characterize the storm activity intensifying in the era of cooling. Sazerna (father and son) wrote that in the last century $\mathrm{BC}$, the production of wine and olives in Italy was complicated by very severe winters [38].

Roman poet Publius Ovidius Naso (43 BC - 18 AD), who was in exile in the Black Sea region since $8 \mathrm{AD}$, writes that the Danube here freezes for three years in a row. It worth noting that even during the period of modern warming, one can cite examples of very severe winters following in a row on the Russian Plain. These are abnormal January frosts with daily records not yet beaten. For example, for St. Petersburg - January 16-19, 1940; January 1-2, 1941; January 20-21, 24, January 27-28, 1942. In the Moscow region, the air temperature on January 17,1940 reached $-51,-53^{\circ} \mathrm{C}$ [46].

Ovidius complaints about the severity of the climate of the west coast of Pontus Euxinus are considered forced. However, the following rhymes require analysis: "Where 
the ships sailed, pedestrians go, and the horse's hoof beats loudly along the iced waters. Along unexpected bridges ... oxen slowly drag the weight of Sarmatian carts" [47]. The question arises: how strong should be the frost to freeze water that it can withstand the weight of the horse and the cart? Dendrochronological temperature anomalies in deviations from the average values for the period 1951-1980, calculated by a group of scientists Klimenko V.V., Matskovsky V.V., Pakhomova L.Yu. for North-Eastern Europe [27], show that the 1 st century $\mathrm{AD}$ was cooler by $0.1-0.4^{\circ} \mathrm{C}$ of this not the warmest period $(1951-1980)$ in the modern era of temperature increase. The coldest was the first half of the 1st century $\mathrm{AD}$. In the initial reconstruction, the anomaly of the decade-long values of the average annual temperature at the beginning of the century reached $-0.5^{\circ} \mathrm{C}$, after data calibration it decreased to $-0.4^{\circ} \mathrm{C}$. This cooling, which began in the first century $\mathrm{BC}$ and continued in the first century $\mathrm{AD}$, we called the Climatic Pessimum of Ovidius (Figure 2).

\section{Conclusions}

Climatic optimums alternate with Little Ice Ages according to a decrease (up to 2-7 cases) and an increase (up to 15-17 cases per century) of the number of years with four and five polar eclipses. Orbital factors are the primary cause of the alternation of the number of years with four and five polar eclipses per century and, accordingly, climatic optimums and pessimums that enhance the growth of mountain glaciers and the ice cover of the oceans.

The precession of the axis of rotation of the Earth and the rotation of the apses line entail millennial rhythms in the advance and retreat of glaciers. Centennial rhythms are associated with a change in the Moon-Earth-Sun orbital configurations, which are visually traced in the form of the movement of the shadow cone of solar eclipses around the globe. Centuries with frequent recurrence of years with four polar eclipses (15-17 cases), the intervals between which are mainly 3, 4, 7 years, coincide with Little glaciations. During the period of Ancient and Medieval optimums, the number of years with four polar eclipses was being reduced to 2-5 cases per century; in modern times, as in the interglacial period of the 14-15th centuries (which coincided with the minimum solar activity of Spörer), up to 67 cases. The intervals between years with 4-5 polar eclipses reached 11, 18 years, sometimes more.

Solar activity $[48,49,50]$, as well as planetary factors and processes - volcanic activity $[29,30,33]$, current intensity, heat transfer with the World Ocean - can significantly strengthen or weaken the influence of gravitational forces due to the configuration of orbits in outer space.

Anthropogenic causes are not the main cause of modern warming [51]. Mikhail Bogolepov, who studied the fluctuations in the climate of European Russia in the historical era from chronicles, suggested in 1908 that we are dealing with "waves of a higher order, the period of which spans several centuries". Sherstyukov B.G. [3, 8] believes that modern climate change is the next phase of its natural fluctuations, on which the greenhouse component is superimposed (its contribution is about $25 \%$ ). He is sure that modern knowledge about the structure and mechanisms of the influence of external factors on the climate system is not enough to build objective physical and mathematical models. Models simplified to one anthropogenic factor are erroneous, and the conclusions about the imminent thermal catastrophe of mankind are greatly exaggerated. Snakin V.V. [2], in the review devoted to global changes in the climate system, also shows the inconsistency and subjective nature of forecasts of global anthropogenic changes in temperature, and gives preference to the natural causes of changes in the climate system.

The results of the study, taking into account other factors [30, 33, 48, 50], can be used in retroanalyzing glaciation events in the centuries $\mathrm{BC}$ and predicting them in the future. 


\section{Acknowledgements}

This work is dedicated to E. Ladurie. Some patterns that were first identified in our studies $[18,23]$ did not always find confirmation in the available literature, but thanks to the work "A History of Climate Since the Year 1000", which is a unique example of a competent approach to scientific historical research, everything fell into place. The fastidious work of the historian Emanuel Le Roy Ladurie [16], who worked with numerous archival primary sources of the Annecy repository, and the objective critical analysis of the research works of the 19-20 centuries, made with due respect to their authors, contributed to the successful solution of the problems in determining the time limits of little glaciation (1590-1850) in Europe and the medieval glaciation of the 12-13th centuries.

\section{References}

1. T. Stocker, D. Qin, G. Plattner, M. Tignor and others, IPCC: Summary for Policymakers. In: Climate Change 2013: The Physical Science Basis. Contribution of Working Group I to the Fifth Assessment Report of the Intergovernmental Panel on Climate Change (Cambridge, Cambridge University Press, 2013) http://climatechange2013.org/

2. V.V. Snakin, Life of the Earth: Interdisciplinary scientific and practical journal 41(2), 148 (2019)

3. B.G. Sherstyukov, Regional and seasonal patterns of changes in the modern climate (Obninsk, Publishing house of RIHMI-WDC, 2008) http://meteo.ru/publish_tr/monogr2

4. G. Patzelt, Jahrbuch der Geologischen Bundesanstalt 156(1-4), 97 (2016)

5. Cato Varro, Columella Pliny, About Agriculture (M.-L., OGIZ-Selkhozgiz, 1937)

6. N.K. Kononova, S.V. Morozova, E.A. Polyanskaya, Global climate changes: regional effects, models, forecasts: Materials of the international scientific and practical conference (Voronezh, Publishing house "Digital Printing", 2019)

7. V.M. Khan, R.M. Wilfand, V.A. Tishchenko, E.N. Kruglova, I.A. Kulikova, E.S. Ganieva, Global climate change: regional effects, models, forecasts: Materials of the international scientific and practical conference (Voronezh, Publishing house "Digital Printing”, 2019)

8. B.G. Sherstyukov, Arctic and North 24, 39 (2016)

9. A.I. Voeikov, The eight-year period of warm winters. Selected works (M., Publishing house of the Academy of Sciences of the USSR, 1952)

10. O.A. Drozdov, Proceedings of the Order of the Red Banner of Labor of the Main Geophysical Observatory named after A.I. Voeikov 274, 3 (1971)

11. T.V. Pokrovskaya, Proceedings of the Order of the Red Banner of Labor of the Main Geophysical Observatory named after A. I. Voeikov "General and synoptic climatology”378, 46 (1976)

12. G.K. Tushinsky, Space and the rhythms of the Earth's nature (M., Education, 1966)

13. A.L. Chizhevsky, The sun and we (M., Znanie, 1963)

14. A.V. Schnitnikov, Intracentury variability of components of general moisture: Essays USSR Academy of Sciences, Geographical Society of the USSR (L., Nauka, 1969)

15. A.V. Schnitnikov, Collection "Modern issues of glaciology and paleo glaciology" (M.-L., Publishing House of the Academy of Sciences of the USSR, 1964) 
16. E.P. Borisenkov, V.M. Pasetskiy, The thousand-year chronicle of extraordinary natural phenomena (M., Mysl, 1988)

17. E. Le Roy Ladurie, A History of Climate Since the Year 1000 (L., Gidrometeoizdat, 1971)

18. L.N. Litvinenko, The Planet Earth system: 200 years since the birth of I.I. Sreznevsky: 100 years since the publication of his dictionary of the Old Russian language, Interdisciplinary Scientific and Analytical Journal "Space and Time" (M., LENAND, 2012) ISBN: 978-5-9710-0498-1

19. L.N. Litvinenko, V.V. Litvinenko, Vestnik of Moscow Region State University, Series: Natural Sciences 3, 23 (2018) DOI: 10.18384/2310-7189-2018-3-23-38

20. L. Zotov, N.S. Sidorenkov, C. Bizouard et al, Geodesy and Geodynamics 8, 433 (2017)

21. N.S. Sidorenkov, Earth and the Universe 3, 25 (2016)

22. N.S. Sidorenkov, Astronomical and Astrophysical Transactions 30(2), 249 (2018)

23. Solar eclipse catalog, Total solar eclipse, http://www.secl.ru/eclipse_catalog.html

24. L.N. Litvinenko, V.V. Litvinenko, Global climate changes: regional effects, models, forecasts: Materials of an international scientific and practical conference (Voronezh, Publishing house "Digital Printing", 2019) ISBN: 978-5-906384-90-4

25. V.A. Klimanov, N.A. Khotinsky, N.V. Blagoveshchenskaya, Bulletin of the Russian Academy of Sciences, Geography Series 1, 89 (1995)

26. V.V. Klimenko, V.V. Matskovsky, D. Dalmann, Arctic: Ecology and Economics 4(12), 84 (2013)

27. V.V. Klimenko, A.M. Sleptsov, Izvestiya RGO 6, 45 (2003)

28. V.V. Klimenko, V.V. Matskovsky, L.Yu. Pakhomova, Man and Nature in space and time 36, 47 (2012)

29. A.M. Sleptsov, V.V. Klimenko, History and Modernity 1, 118 (2005)

30. D.H. Abbott, P. Biscaye, J. Cole-Dai, D. Breger, Magnetite and Silicate Spherules from the GISP2 Core at the 536 A.D. Horizon, American Geophysical Union, Fall Meeting, bibcode 2008AGUFMPP41B1454A, Astrophysics data system (2008) https://ui.adsabs.harvard.edu/

31. U. Büntgen, V.S. Myglan, F.C. Ljungqvist et al, Nature Geoscience 9(3), 231 (2016)

32. U. Büntgen, W. Tegel, K. Nicolussi et al, Science 331(6017), 578 (2011)

33. U. Büntgen, L. Wacker, J.D. Galvan et al, Nature Communications 9 (2018) DOI: 10.1038/s41467-018-07636-6

34. A. Gibbons, Archaeology: Why 536 was «the worst year to be alive» (2018) https://www.sciencemag.org/news/2018/11/why-536-was-worst-year-be-alive

35. H.W. Linderholm, M. Nicolle, P. Francus et al, Climate of the Past 14, 473 (2018)

36. F.C. Ljungqvist, Geografiska Annaler 92A(3), 339 (2010)

37. V. Matskovsky, International Journal of Climatology 36(9) (2015) https://rmets.onlinelibrary.wiley.com/doi/full/10.1002/joc.4563

38. F. Espenak, J. Meeus, Periodicity of Solar Eclipses, NASA Eclipse Web-Site https://eclipse.gsfc.nasa.gov/SEsaros/SEperiodicity.html

39. E.P. Borisenkov, V.M. Pasetskiy, The thousand-year chronicle of extraordinary natural phenomena (M., Mysl, 1988)

40. F. Mayr, Untersuchungen liber Ausmass und Folgen der Klima und Gletscher schwankungen seit dem Beginn der postglazialen Warmezeit. Ausgewahlte Beispiele 
aus den Stubaier Alpen in Tirol. Zeitschrift fiir Geomorphologie (1964)

41. Climate change over the past 2000 years, Center for Climate Change in the Kyrgyz Republic, http://climatechange.kg/wp-content/uploads/2013/11/klimat-nash-ery.pdf

42. Yu.K. Vasilchuk, Yu.N. Chizhova, V. Papesh, N.A. Budantseva, Cryosphere of the Earth X(1), 56 (2006)

43. M.G. Grosswald, Half a century in the search for echoes of the great glaciations, RAS, Institute of Geography (M., Scientific World, 2004)

44. P. Holmberg, B. Gräslund, O. Sundqvist, H. Williams, Futhark: International Journal of Runic Studies 9-10, 7 (2020) DOI: 10.33063/diva-401040

45. V.V. Klimenko, Vostok 4, 5 (1998)

46. V.V. Klimenko, Vostok 1, 5 (2000)

47. Applied scientific reference book on the climate of the USSR: Issue 8 (L., Gidrometeoizdat, 1990)

48. N.D. Volpin, S.V. Shervinsky, S.A. Osherova, M.L. Gasparova, Publius Ovidius Naso: Mournful Elegy: Letters from Pontus: Book III, Translation from lat. (M., Publishing House "Nauka", 1978) http://ancientrome.ru/antlitr/t.htm?a=1303007003

49. E.P. Popova, V. Zharkova, S. Shepherd, S. Zharkov, Journal of Atmospheric and Solar-Terrestrial Physics 1 (2017)

50. V. Zharkova, S. Shepherd, E. Popova et al, Geophysical Research Abstract, EGU General Assembly 20 (2018) EGU2018-8066-1-EGU2018-8066-1

51. V.V. Zharkova, S.J. Shepherd, H. Popova, S.I. Zharkov, Reinforcing the double dynamo model with solar-terrestrial activity in the past three millennia arXiv:1705.04482, 1 (2017)

52. V.S. Dietrich, Fascinated by rock and ice (Tirol, 2004) https://archive.is/F8cSS 